\title{
LA SOCIOLOGIA DE GEORG SIMMEL SEGÚN MAX WEBER
}

El texto que presentamos a continuación es una de las críticas más importantes de la sociología tealizada por Max Weber (1864-1920) a su amigo y colega Georg Simmel (1858-1918). ${ }^{1}$ Inédita en castellano hasta hoy, también aparece inacabada, pues Weber nunca quiso terminarla y la guardó en un cajón. Su publicación ayuda a entender las relaciones entre estos dos intelectuales de la «generación de 1890» (así ha llamado H. S. Hughes a estos dos pensadotes, entre otros como Durkheim, Tönnies, Michels, Pareto e incluso Freud). EI manuscrito fue descubierto en el Instituto Max Weber, de la Universidad de Munich, y reproducido en inglés en 1972.2

La presente recensión (inacabada) escrita por Max Weber incluye una visión crítica de las dos obras fundamentales de Simmel, Pbilosophie des Geldes (Leipzig: Duncker und Humblot, 1900), 554 pp.; y Soxiologie: Untersuchungen über die Formen der Vergesellschaftung (en la misma editorial, 1908), 782 pp. La Soziologie de Simmel, publicada en 1908, es

1. Sobre las relaciones intelectuales entre Simmel y Weber, pueden verse: Donald N. Levine (comp.), Georg Simmel: On Individuality and Social Forms (Chicago: The University of Chicago Press, 1971); Kurt H. Wolff (comp.), Georg Simmel, 1858-1918: A Collection of Essays, with Translations and a Bibliograpby (Columbus: Ohio State University Press, 1959); sobre todo los capítulos de F. H. Tenbruck (pp. 61.99), y Heinz Maus (pp. 180-200). Y Ia introducción de Kurt $\mathrm{H}_{2}$. Wolff, The Sociology of Georg Simmel (Nueva York: Free Press, 1950).

2. Putede verse: «Georg Simmel as sociologist, by Max Weber», en Social Research, vol. 39 , núm, 1 (1972): 155-163. 
en el fondo una colección de sus artículos aparecidos entre 1890 y $1907 .^{3}$ La recensión original se titulaba «Georg Simmel como sociólogo y teórico de la economía del dinero», ${ }^{4}$ y fue escrita seguramente en 1908, tras la publicación de la Soziologie. Dado el nivel crítico, es obvio que Weber decidiese no publicarla para no poner más obstáculos al acceso de Simmel a una posición estable en la Universidad de Heidelberg.

El impacto de Simmel en Weber es considerable. Uno de los primeros libros que Max Weber lee después de su enfermedad mental ${ }^{5}$ es la Pbilosopbie des Geldes. Sin embargo, se desmarca progresivamente de esa influencia. En Economía y Sociedad, Weber apenas menciona ya a Simmel, salvo en la introducción, y en forma crítica: «De la metodología de Simmel difiero en la separación que llevo a cabo, siempre que ha sido factible, entre sentido mentado y sentido objetivamente válido, los cuales Simmel no solamente no distingue siempre, sino que con frecuencia permite de modo deliberado que se deslicen confundidos. ${ }^{6}$ Las páginas que aquí se incluyen desarrollan esas diferencias.

La recensión - a pesar de no haberse publicado en vida de Webersugiere que la estrecha amistad de Simmel y Weber estaba llena de ambigüedades, sobre todo a partir de 1908. Es, además, la única revisión crítica que Weber escribiese de la sociología de Simmel. Precisamente de ahí su importancia.

Desgraciadamente la infuencia de Simmel en la sociología española es hoy aún menor que en los años veinte y treinta. En cierta forma es preciso recuperar a Simmel, pero no a través del pensamiento orteguiano o parsoniano, sino de la nueva microsociología y de la sociología crítica.

3. La Soziologie no se publica en castellano hasta 1927 (Madrid: Revista de Occidente, 2 vols.) curiosamente por sugerencia personal de Jose Ortega y Gasset. Existe una segunda edición en 1977. La Philosophie des Geldes no se traduce hasta 1976 (Madrid: Instituto de Estudios Políticos).

4. «Georg Simmel als Soziolog und Theoretiker der Geldwirtschaft».

5. Marianne Weber, Max Weber; A Biography (Nueva York: Wiley, 1975), pp. $252-253$.

6. Max Weber, Economía y sociedad, 2a. ed. (México: Fondo de Cultura Económica, 1969), vol. 1, p. S. La ptimera edición en alemán es de 1922. 


\title{
LA SOCIOLOGIA DE SIMMEL
}

\author{
Max Weber
}

Los juicios sobre la obra de Georg Simmel muestran un alto nivel de contradicción. Por una parte, se tiende a reaccionar ante la obra de Simmel desde un punto de vista arrolladoramente antagónico. Especialmente, hay aspectos cruciales de su metodología que resultan inaceptables. Sus resultados sustantivos han de ser con frecuencia inhabitual considerados con teservas, y no es tato tener que rechazarlos por entero. Además, su modo de exposición es en ocasiones chocante y extraño, y resulta, cuando menos, antipático. Por otra parte, uno se siente totalmente obligado a afirmar que tal modo de exposición es simplemente brillante $y$, lo que es más importante, llega a resultados que le son propios y que no pueden ser alcanzados por ningún imitador. En realidad, casi todos sus trabajos abundan en importantes ideas teóricas nuevas y en las más sutiles observaciones. Prácticamente todos pertenecen a ese tipo de libros en que no sólo los descubrimientos válidos, sino también los falsos, contienen abundantes estímulos para el propio pensamiento posterior y en comparación con los cuales la mayoría de las más apreciables realizaciones de otros estudiosos parece exudar un peculiar olor a escasez y miseria. Lo mismo puede afirmarse de sus fundamentos epistemologicos y metodológicos y, otra vez, precisamente en lo que tienen de decididamente indefendible. En conjunto, Simmel, incluso cuando avanza por un camino equivocado, salva plenamente su reputación como uno de los primeros pensadores, un estímulo de primera línea para la juventud académica y los colegas académicos (en la medida en que el espíritz de estos últimos no esté demasiado apagado nì su vanidad y/o 
mala conciencia demasiado vivaz para permitirles sex "estimulados» por un hombre de cincuenta años que no ha llegado más allá de la situación de extraordinarius * y que, consecuentemente, pertenece a las filas de los fracasados).

¿Cómo armonizar estos juicios contradictorios? Por medio de una crítica del estilo científico de Simmel en sus dos principales escritos sociológi$\cos ^{* *}$ Las siguientes consideraciones pueden contribuir a responder la pregunta y a enjuiciar la actitud de Simmel como científico, tema que resulta peculiarmente problemático en muchos aspectos.

Es preciso decir que no plantea problema ninguno el hecho de que Simmel esté privado del reconocimiento «oficial» que supondría la concesión de la categoría de ordinarius *** que ha merecido más que sobradamente bace década y media. Las causas de ello, que son de lo más banal, son conocidas en Berlín y en Prusia por cualquiera que se tome la molestia de enterarse. Y fuera de Prusia la experiencia ha demostrado que todos los esfuerzos de otras facultades para teclutar a Simmel resultarán inútiles mientras los intermediarios responsables no se decidan ya a emanciparse de esas eminencias prusianas que se sentirian relegadas ante cualquier nombramiento conferido a Simmel. Mucho más problemático resulta el hecho de que, aparte de cierto entusiasmo acrítico por Simmel, que objetivamente poca cosa dice, y dejando de lado la existencia de un grupo de jueces intelectuaimente eminentes $y$ en alto grado competentes, que aun criticando detalles de su obra otorgan a Simmel pleno reconocimiento sin reservas, lo cual objetivamente dice bastante, existe no sólo gran número de especialistas en filosofía que le detestan abiertamente -el típico carácter sectario de las «escuelas» filosóficas de la época, a ninguna de las cuales pertenece Simmel, lo hace fácilmente comprensible (dejando de lado otros motivos que pueda haber)-, sino que hay además estudiosos que hay que tomar muy en serio dedicados a disciplinas que lindan con el campo de trabajo sociológico de Simmel y que se inclinan, por lo menos respondiendo a una concisa indagación, a reconocer la etudición de Simomel en ciertos detalles y a techazar su trabajo en conjunto. Entre los economistas, por ejemplo, se pueden observar explosiones de ira injustificada en su contra -hasta se ha dado publicidad a pormenores de tales manifestaciones- y del mismo círculo de especialistas proviene la consideración de que la habilidad de Simmel es en definitiva «dividir el aixe y volverio a juntar». Ahora bien, esta actitud, bastante extendida, y que en ocasiones tiende a la malevolencia, sospechosamente nunca se ha convertido en una crítica sistemática y

* Similar a uprofesor agregado» no numeratio. (N. del $E$.)

** Se refiere a Soziologie y Philosopbie des Geldes. (N. del E.)

*** Catedrático numerario. (N. del E.) 
coherente de Simmel. Por el contrario, la totalidad de sus críticos serios hasta el momento se han visto en una situación como lo que yo confesaba en mí mismo antes. De todos modos, esta actitud debe estar adecuadamente fundamentada al menos en su existencia, ya que no como juicio de valor. Ese ridículo santiguarse ante el nombre «Sociología» que otros estudiosos de indudables méritos y de primera fila tienen que aguantar continuamente en Alemania, y que sigue en pie, no llega en este caso a explicat el tono de animosidad que resulta evidente al observador atento. Para entenderlo bastará con hacer una puntualización muy general: Simmel extrae ejemplos de las más variadas zonas del conocimiento para ilustrar un tema sociológico, y frecuentemente lo hace en forma de «analogía». Este procedimiento analógico será criticado por lo dudoso de sus principios básicos (cosa que se acentúa especialmente en el tratamiento que da Simmel a los problemas sociológicos).

Ahora bien, se da con frecuencia el caso de que para los propósitos concretos de Simmel la «analogía» puede ser tolerablemente empleada; pero los especialistas que han de considerarlos según su naturaleza intrínseca o en su contexto específico, inevitablemente deben, desde $s u$ punto de vista, consideras su aspecto «análogo» como algo «externo». Se ha de considerar el fenómeno de tal modo construido como algo enteramente concebido de modo "tangencial» en su «esencia» y no comprendido en to que se refiere a sus componentes causales. No se trata de una diferencia accidental, sino, como se discutirá, se basa en la formación de la «analogía», que Simmel considera útil para sus propósitos. Y precisamente porque al mismo tiempo que se comete este error (desde el punto de vista del especialista) se presenta una cantidad sustancial de trabajo intelectual creativo, y porque además no encontrará tan fácil analizar las últimas bases de su propia impresión de que hay un «error» presente, tras cierto número de experiencias similares el economista profesional arrojatá amargamente el libro a un rincón y así acabará su enjuiciamiento del mismo. Habitualmente, o por lo menos con mucha frecuencia, el punto decisivo es que donde el especialista trata asuntos de «facticidad», cuestiones empíricas, Simmel se vuelve a considerar el «sentido» que podemos extraer del fenómeno (o que creemos que podemos).

No es éste el lugar para indagar si los filósofos colegas de Simmel, al encontrar difíciles los problemas lógicos y filosóficos utilizados por Simmel como «analogías» para ejemplificar asuntos de lo más heterogéneo, no encontraxán en este procedimiento, que desde luego en ocasiones choca como si fuera una «broma», una justificación para no ocuparse de él seriamente; y esto sin considerar el asunto de si Simmel, por su parte, consigue sus objetivos con este procedimiento. Porque los últimos intereses de Simmel 
están dirigidos a problemas metafísicos, al «sentido» de la vida. Como estos intereses son muy evidentes en su tratamiento de asuntos técnicos sustanciales, es demasiado fácil descuidar el hecho de que, con todo, Simmel pro. bablemente ha contribuido más al avance de los asuntos técnicos sustanciales de su disciplina, incluso si en ocasiones tienen más la naturaleza de un "subproducto», que un número considerable de profesores de filosofía de la categoria que se ha hecho hoy habitual en conjunto.

Pero ya es suficiente. Las anteriores observaciones había que hacerlas, pero ello no significa que tengamos intención ninguna de convencer a las personas que ya tienen un juicio formado al respecto del significado de Simmel. Sin entrar en tales consideraciones, mi objetivo es examinar su estilo sociológico de trabajar en sus dos principales obras sociológicas tanto en lo que se refiere al método como a la esencia. No hay motivo especial para que debamos detenernos demasiado tiempo en las explicaciones del propio Simmel sobre la naturaleza de la sociología y el sentido de su método sociológico; más bien preferimos captar su método examinando el modo que tiene de tratar problemas individuales. En cierto período, cuando los sociólogos a quienes se podía tomar verdaderamente en serio mantenían la tesis de que la única tarea de la teoría sociológica es la definición del concepto de sociedad, estos asuntos tenían que ser tratados de antemano.*

Para hablar en los términos más generales, etmpezaremos por la «so ciologia», que para Simmel es una ciencia dedicada a «interacciones» entre individuos. Ahora está claro que el concepto de «interaccion» tiene una buena dosis de ambigüedad. En su sentido más amplio como influencia reciproca de varias (por delimitadas que estén) «unidades», se dan «interacciones», por ejempio, en mecánica, física, química y en todas las ciencias naturales en los más múltiples matices, con el resultado de que su existencia general se ha considerado entre los «axiomas».

La gravedad es siempre gravedad recíproca; no sólo la colisión de dos cuerpos que se muevan en diferentes direcciones, sino también el choque de un cuerpo móvil contra otro quieto, afecta a ambos (por transmisión de movimiento, alteración de la velocidad y dirección de la energía cinética y generación de calor). Claro que en general se puede decir que en el

* Aquí resulta relevante la perspicaz crítica que hizo el doctor $O$. Spana de algunos puntos esenciales referentes a los conceptos de Simmel de «sociedad» y «sociología», si bien la bizo antes de la aparición de la útima obra de Simmel (Soziologie). Me reflero a lo expuesto en su libro Wirtschoft und Gesellschaft (Dresde, 1907), especialmente en las páginas 192 y ss. En lo sucesive no citaré esta obra en cada observación particular. En cuanto a los principales puntos de acuerdo o desacuerdo, haré algún comentario. En lo que se refiere a la primera obra criticada por Spann, la Soziologie de Simmel recientemente publicada muestra algunas modifucaciones notables pero no fundamentales. 
campo de Ia realidad física una influencia que no sea «recíproca» en el zaás estricto sentido de la palabra y como fenómeno general apenas es concebible. Esto es cierto incluso respecto de las radiaciones solates de la tierra. Aunque la tierta sólo recibe una cantidad mínima de las energías térmica y luminosa de los rayos del sol, esto, debido a la radiación inversa, ejerce alguna influencia recíproca en el sol; aunque sea inconmensurablemente pequeña, no es nula en comparación con los quanta de rayos que brotan del universo abierto.

Por tanto, cuando se nos dice en la Soziologie de Simmel (página 134) que una «interacción» está en la base del "abstracto deseo de dominio» cuya satisfacción depende del hecho de que la acción o padecimiento de otro (no importa qué forma adopte) muestre la influencia de la persona dominante; y cuando uno interpreta esto, como inevitablemente ha de ha. cerlo, como expresión de que el mismo efecto se logra por la mera posibilidad de infuenciar (el destino de otros, incluso de aquellos otros de cuya existencia no tiene noticia la persona dominante, del mismo modo que, a la inversa, el partido infuenciado -como muchas veces puede testimoniarse suficientemente durante la instrucción de los reclutas- posiblemente puede no tener ningún conocimiento del nombre y existencia concreta del «comandante», conociendo sólo a sargentos, cotoneles, suboficiales, etc.), en consecuencia, como en este ejemplo del mundo físico, uno encontratá este ejemplo de «interacción» tan extendido que sólo con la mayor de las artificiosidades podrá conceptuar una pura influencia en una dirección, como, por ejemplo, la de una persona influida por otra en que no haya algún elemento de «interacción» [...].*

* La recensión aparece inacabada. (N. del E.) 